\title{
Effect of bonding or unbonding on seismic behavior of bridge elastomeric bearings: lessons learned from past earthquakes in China and Japan and inspirations for future design
}

\author{
Nailiang Xiang ${ }^{1 *}$ (D) Yoshiaki Goto ${ }^{1}$, M. Shahria Alam² and Jianzhong Li $^{3}$
}

\footnotetext{
* Correspondence: ko.noryo@nitech. ac.jp

${ }^{1}$ Department of Civil Engineering, Nagoya Institute of Technology, Nagoya 466-8555, Japan

Full list of author information is

available at the end of the article
}

\begin{abstract}
Economical laminated elastomeric bearings are well-adopted options for load transmission components of bridges from superstructure to substructure. In most cases, the design of such elastomeric bearings primarily depends on the requirements from service-level conditions such as superstructure thermal movements, with little consideration of extreme loads like earthquakes. However, bridge elastomeric bearings are very likely to be subjected to earthquake hazards, particularly for bridges located in high seismic regions. This study presents an overview of the observed typical damages of bridge elastomeric bearings in the past major earthquakes mainly in China and Japan. Comparisons of different damage patterns are conducted based on the different installations of bridge elastomeric bearings (bonding or un-bonding). The effect of bearing installation methods on the overall seismic behavior of bridges is also discussed. A desirable installation method for bridge elastomeric bearings against strong earthquake loads is recommended, which is expected to overcome the critical limitations of current design practice.
\end{abstract}

Keywords: Bridges, Laminated elastomeric bearings, Bonding, Un-bonding,

Earthquake damages, Seismic performance

\section{Introduction}

Laminated elastomeric bearings are attractive bearing options in small to medium span bridges mainly due to the low cost associated with their design, fabrication, construction, and maintenance. Such bearings are usually designed to satisfy the service-level requirements by not only sustaining the vertical dead-loads but also accommodating the horizontal movements of superstructure induced by service actions, such as temperature, concrete creep and shrinkage, and vehicle braking. Regarding the installation methods of elastomeric bearings in bridges, three practices can be found across the world, which are fully bonded, fully unbonded, and single-side bonded. The fully

(c) The Author(s). 2021 Open Access This article is licensed under a Creative Commons Attribution 4.0 International License, which permits use, sharing, adaptation, distribution and reproduction in any medium or format, as long as you give appropriate credit to the original author(s) and the source, provide a link to the Creative Commons licence, and indicate if changes were made. The images or other third party material in this article are included in the article's Creative Commons licence, unless indicated otherwise in a credit line to the material. If material is not included in the article's Creative Commons licence and your intended use is not permitted by statutory regulation or exceeds the permitted use, you will need to obtain permission directly from the copyright holder. To view a copy of this licence, visit http://creativecommons.org/licenses/by/4.0/. 
bonded bearings are those having the top and bottom surfaces securely bonded to the superstructure and substructure, respectively, whereas the fully unbonded ones are treated oppositely. The fully unbonded elastomeric bearings are usually placed directly between the superstructure and substructure without any connection expect the friction at contact surfaces. Bridge elastomeric bearings in Japan always adopt the fully bonded installation (JRA 2018), which can make full use of the shear deformation capacity of rubber. One common detailing is that bearings are first vulcanized to end plates that are then bolted to the superstructure and substructure. Compared with welding, bolting makes it easier for bearing replacement. By contrast, highway bridges in China prefer to use fully unbonded elastomeric bearings mainly out of the convenience of construction (Xiang and Li 2016). For concrete bridges, for example, the top side of unbonded bearings are usually in contact with an embedded steel plate in concrete girders, while the bottom side is seated directly upon concrete substructure. The single-side bonded elastomeric bearings are common in bridges of the United States, particularly for those with steel superstructure and concrete substructure (AASHTO/ NSBA 2004). The bearings can be secured to the top steel girders by either welding or bolting depending on the preference in different states. The bottom surface of bearings is directly placed on concrete substructure since the positive connection between bearing and concrete is usually difficult to implement.

In most countries, the design and implementation of bridge laminated elastomeric bearings are mainly intended for service-level conditions with little consideration of seismic loads. Displacement restrainers like shear keys are often utilized in parallel with the bearings to control the bearing displacements. Although laminated elastomeric bearings are not the essential part of the earthquake resistant members of bridges, they are inevitably subjected to the dynamic loads when strong earthquake strikes. The seismic behavior of elastomeric bearings will be different for different bearing installation methods. The 2008 Wenchuan earthquake in China witnessed extensive damages of bridge elastomeric bearings, mainly in the form of bearing permanent offset from the original position ( $\mathrm{Li}$ et al. 2008; Han et al. 2009). Another typical damage was the failure of shear keys, which just reduced the lateral restraints for elastomeric bearings. Due to the bearing offset and shear key failure, the displacement of bridge superstructure would be extremely large, which was the primary cause of the span collapse observed in the earthquake. The seismic offset damage of unbonded elastomeric bearings was also seen in the 1999 Chi-Chi earthquake (Chang et al. 2000) and the 2010 Chile earthquake (Kawashima et al. 2011). However, during the recent earthquake events (the 2011 Great East Japan earthquake and the 2016 Kumamoto earthquake) occurred in Japan (Kawashima 2012; Akiyama et al. 2016), bridge elastomeric bearings displayed a totally different damage pattern due to the fully bonding installation practice. During the earthquakes, some laminated elastomeric bearings were found fully ruptured in shear direction, which caused the separation between superstructure and substructure without the restraints from the bearings. The rupture was observed either in the bearing bodies or the bolt connections. Following the bearing rupture, the unrestrained superstructure would be more easily to move, and some bearing unseating cases occurred because of that. Regarding the single-side bonded elastomeric bearings, since they have been rarely encountered with strong earthquake, little earthquakeinduced damages was reported. It is obvious to conclude from the aforementioned 
bearing earthquake damages that the installation options play a critical role in the damage pattern and seismic behavior of bridge elastomeric bearings. Hence, it is essential to explicitly specify the effect of bearing installation methods and find a desirable option for seismic considerations.

This study first reviews the different damage patterns of bridge laminated elastomeric bearings observed in the recent earthquakes mainly in China and Japan. According to the different bearing installation practice in these two countries, the possible damage mechanism and process of the elastomeric bearings under strong earthquakes are deduced. Then, the effect of bearing installation methods on the seismic performance of bridges is discussed in both favorable and adverse aspects. Finally, a desirable installation option for laminated elastomeric bearings is proposed to be better suited for strong earthquake loads, and some corresponding critical design issues are highlighted.

\section{Typical earthquake damage of bridge elastomeric bearings}

It is evident to say that the damage pattern of bridge elastomeric bearings largely relies on the bearing installation methods, e.g., bonding, un-bonding. The recent earthquakes occurred in China and Japan, which are the 2008 Wenchuan earthquake, the 2011 Great East Japan earthquake, and the 2016 Kumamoto earthquake, witnessed various damage/failure patterns of elastomeric bearings, including bearing sliding and rollingover, bearing body rupture, fracture of bolt connection, and bearing unseating, which will be presented and discussed as follows in this section.

\subsection{Fully unbonded elastomeric bearings in China}

As previously described, the fully unbonded elastomeric bearings are characterized by having their top and bottom surfaces in direct contact with the superstructure and substructure, respectively, without any positive connections except friction. Hence, under strong earthquake loads, the surface friction is very likely to be exceeded, and some unstable bearing behavior will occur. It has always been a common practice in China that small to medium span highway bridges adopt such a unbonded installation method for bridge elastomeric bearings (Xiang et al. 2018), as seen in Fig. 1a. During the 2008 Wenchuan earthquake occurred in China, the unbonded elastomeric bearings suffered from extensive damages ( $\mathrm{Li}$ et al. 2008; Han et al. 2009), as shown in Fig. 1b-d. It can be seen from Fig. 1b that some of the unbonded elastomeric bearings were encountered with squeezing and curling deformations under lateral seismic loads. Such deformations are common when the bearing surfaces are unrestrained. The combined squeezing and

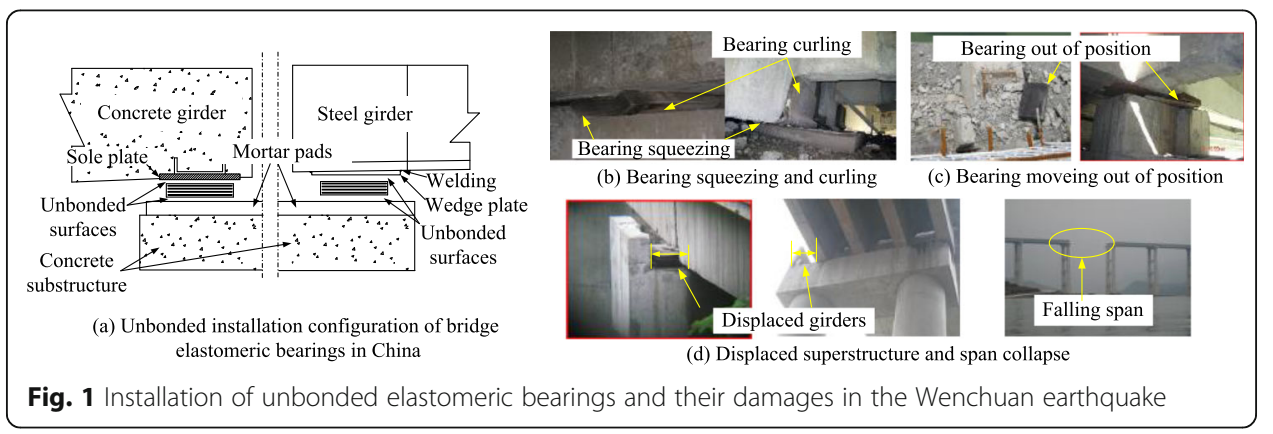


curling deformations are also referred to as the rolling-over response of elastomeric bearings. Additionally, a lot of elastomeric bearings were found permanently displaced out of the original position and lose vertical support capacity partially or totally, as seen in Fig. 1c. The unbonding of elastomeric bearings also made the bridge superstructure displaced excessively due to lack of adequate restraints from the bearings. Some catastrophic span falling cases were also observed due to the excessively large superstructure displacement yet inadequate support length, as shown in Fig. 1d.

It is worth noting that similar damage phenomenon associated with elastomeric bearings was also observed in some of the bridges during the 1999 Chi-Chi earthquake (Liu et al. 2006) and the 2010 Chile earthquake (Kawashima et al. 2011), although it was not a common case in these regions. One of the common damage characteristics was the excessively displaced bridge superstructure relative to the substructure due to the unrestrained state of elastomeric bearings. Such a damage pattern was usually the direct cause of the span collapse found in the earthquakes.

\subsection{Fully bonded elastomeric bearings in Japan}

Different than the practice in China, bridges in Japan prefer to use fully bonded elastomeric bearings, which is also specified in the Japanese bridge bearing design code (JRA 2018). As a common practice, elastomeric bearings are bolted to the superstructure and substructure through set plates (Fig. 2a). There are two main reasons accounting for the fully bonding installation practice in Japan: one is because that Japan is a high seismic country, where using fully bonding elastomeric bearings can make full use of the shear stiffness of bearings to restrain the superstructure displacement against earthquake loads; another reason is that steel superstructure and substructure are common in Japanese bridges, which facilitates the mechanical connections between elastomeric bearings and bridges. Figure $2 \mathrm{~b}$ shows the failure pattern of the fully bonded elastomeric bearings observed in the 2011 and the 2016 earthquakes in Japan, where it can be seen that the damage of bonded bearings occurred essentially in the form of bearing rupture (Kawashima 2012; Akiyama et al. 2016; Goto et al. 2017a). The rupture appeared in either the bearing bodies (e.g., rubber-steel delamination, rubber tearing) or the connections (e.g., bolt fracture). As the result of the total bearing rupture, the bearings were

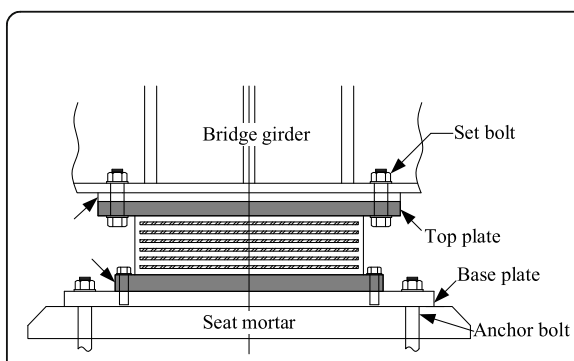

(a) Installation practice in Japan

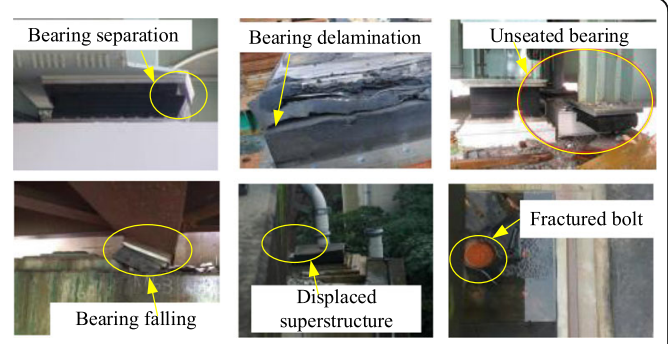

(b) Earthquake damage of bonded elastomeric bearings

Fig. 2 Typical installation of fully bonded elastomeric bearings in Japan and their damages in the 2011 and 2016 earthquakes 
separated into two parts, and some superstructure unseating cases were therefore observed, as shown in Fig. 2b.

For example, during the 2011 Great East Japan earthquake (Kawashima 2012), the six-span East Sendai Viaduct had 18 out of 66 elastomeric bearings totally ruptured by the strong earthquakes, causing the bridge girders to fall off the supports partially or totally. For the Okirihata Oh-hashi Bridge in the 2016 Kumamota earthquake (Akiyama et al. 2016), the bearing rupture occurs at the connecting bolts from the top. The top bolts of the elastomeric bearings at the abutment were totally sheared off, which was unexpectedly against the basic design requirements in Japan that the bolts should be designed as capacity protected members that should not fail prior to the bearings.

\section{Possible seismic damage mechanisms of elastomeric bearings}

\subsection{Fully unbonded elastomeric bearings}

The possible seismic damage mechanism and process of fully unbonded elastomeric bearings is presented in Fig. 3, which can be described as follows: 1) as the earthquake initiates at a small amplitude, the bearing response is dominated with shear deformations with some squeezing and curling deformation appeared respectively at the leading and trailing edges of the contact surfaces. The occurrence of squeezing and curling, in other words, indicates the start of bearing rolling over response; 2) with the increase of earthquake amplitude, the rolling-over movements gradually accumulate, which usually combines with the sliding frictional response at the contact surface. The sliding is activated as soon as the lateral force demand exceeds the critical frictional force; 3) Under the combined action of rolling-over and frictional sliding, the relative displacement between superstructure and substructure gradually increases. Besides, due to the lack of bonding, the elastomeric bearings will also be moving away from their original positions until the bearing unseating eventually occurs, as indicated in Fig. 3.

Figure 3 also plots the force diagram of the unbonded elastomeric bearings between superstructure and substructure under the lateral seismic loads. It can be seen from the

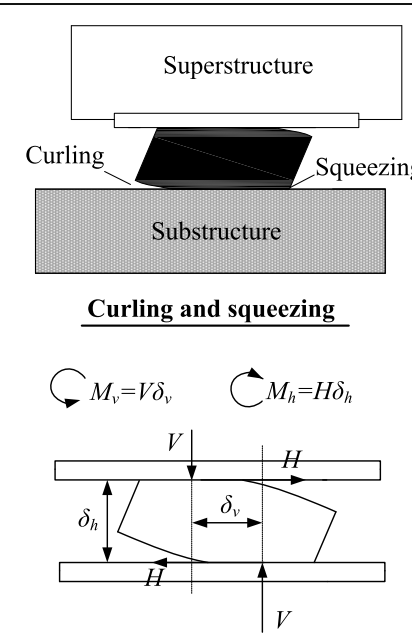

Force diagram
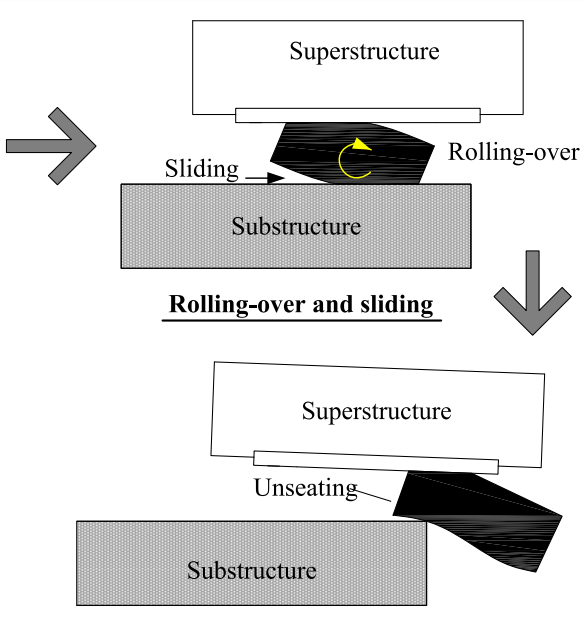

Falling off from support

Fig. 3 Seismic damage mechanism of fully unbonded bridge elastomeric bearings 
diagram that in addition to the frictional force-induced moment at the top and bottom surface $\left(H \delta_{h}\right)$, there exists a vertical force-based moment $\left(V \delta_{v}\right)$, which is induced by the top and bottom curling phenomena as well the P-delta effect. It should be noted that $H \delta_{h}$ shows an overturning effect on the bearings, whereas $V \delta_{v}$ has an opposite antioverturning action. The relative amplitude between the overturning and antioverturning moments governs the bearing responses. If $V \delta_{v}$ can reach no smaller than $H \delta_{h}$, the elastomeric bearings will show a consistent frictional sliding response with a constant rolling-over deformation. Otherwise, the response of elastomeric bearings will be dominated by a rigid-body-like rotations with increasing rolling-over deformation till bearings are squeezed out from between the superstructure and substructure. It can be implied from Fig. 3 that taller bearings with smaller shape factors are more likely to have rolling-over responses due to the larger overturning moment. Compared with pure frictional sliding responses, the rolling-over responses of elastomeric bearings have some critical demerits that should be addressed. First, it is difficult to simulate the behavior of rolling-over using the conventional finite element techniques since such an unstable response is always associated with some complicated behaviors, such as superstructure lift-up, torsional moment, surface contact area variations, etc. Second, the rolling of elastomeric bearings with severe curling and squeezing deformations usually yields high stresses that may lead to the buckling or fracture of the internal steel shims under extreme conditions. Hence, the rolling-over responses of unbonded elastomeric bearings should be avoided as much as possible during strong earthquakes.

\subsection{Fully bonded elastomeric bearings}

Before discussing the damage mechanism of the bonded elastomeric bearings, it is necessary to clarify the various force components acting on the bearings subjected to seismic loads. The possible force components include the shear and compressive forces, tensile force, vertical force-induced bending moment, and pure bending moment. The shear and compressive forces are obvious considering that bearings are subjected to lateral seismic loads while sustaining the dead-load from superstructure. The tensile force of elastomeric bearings will appear for continuous superstructure with non-uniform settlement between adjacent substructures. The vertical force-induced bending moment usually arises from the P-delta effect due to the combined actions of dead load and large shear deformation. Regarding the pure bending moment, in most cases it appears when the upper surface of the substructure rotates round the transverse axis due to the significant flexural deformation. Stiff substructures like abutment and short piers will be unlikely to show such a phenomenon except when the rigid body like rotation occurs due to the failure of substructure foundations. Normally, the failure mechanisms of the bonded elastomeric bearings are dominated by the interaction among different types of force components.

Figure 4a shows two failure mechanisms of bonded elastomeric bearings associated with bearing body rupture and connecting bolt fracture. Typically, a bonded elastomeric bearing will fail under seismic loads in the following way: when earthquake excitation begins, the bearing will experience strain/stress demands under the combined actions of axial force, shear force, and bending moment. When the seismic demands of the bearing exceed a certain capacity limit, the bearing failure will be initiated. For the 


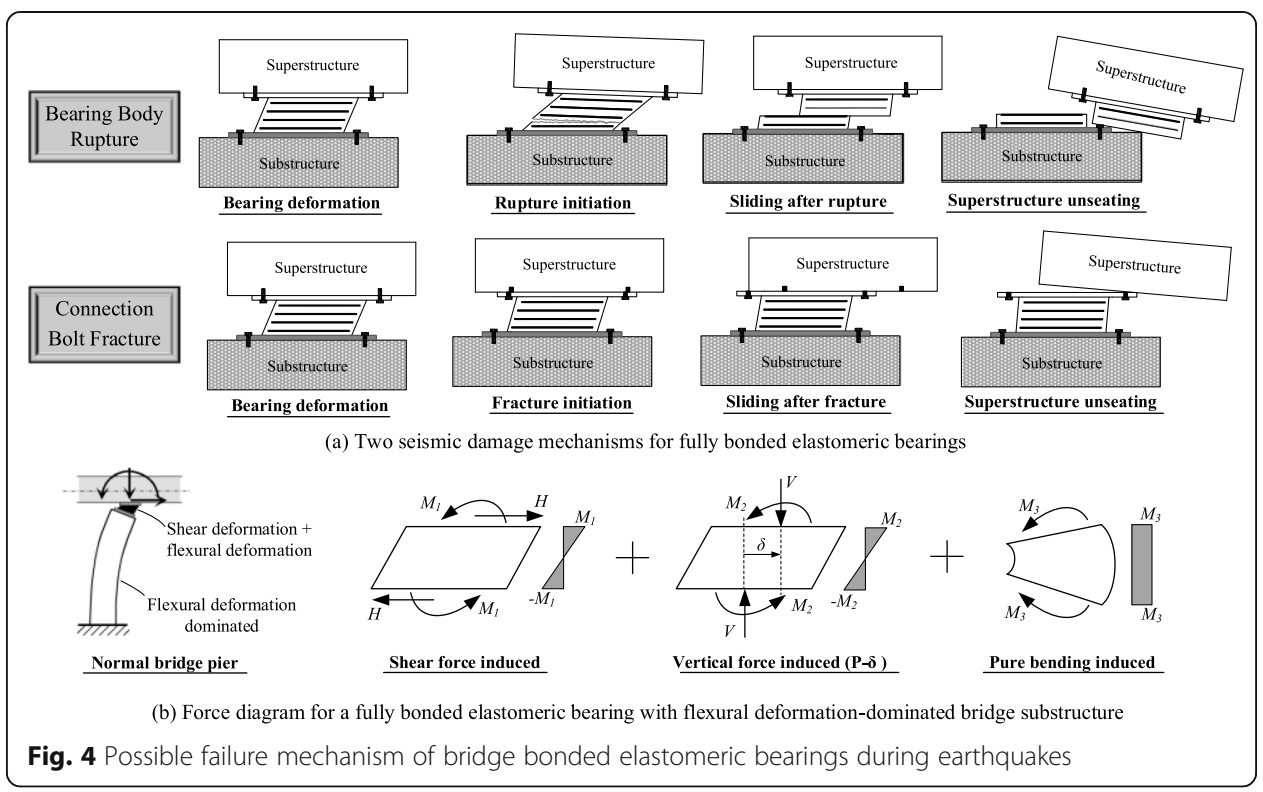

damage pattern of bearing body rupture, the internal rupture of bearing initiates and propagates inwards until the total delamination. As for the fracture of the connecting components, the set bolts will be sheared off at either the top or bottom of the bearing. No matter which failure pattern occurs, the superstructure and substructure will be separated, and the superstructure will then slide relative to the substructure along the ruptured surface. Hence, it can be implied that the ultimate failure pattern of fully bonded elastomeric bearings under extreme seismic loads would probably be the unseating of superstructure following the rupture of bearings. Even if on direct unseating of superstructure is observed, the unrestrained bearing parts after the rupture will also lead to a large residual superstructure displacement following earthquakes. For instance, in the East Sendai Viaduct during the 2011 earthquake, the post-earthquake residual displacements of superstructure at No. 56 Pier were $103 \mathrm{~mm}$ and $653 \mathrm{~mm}$, respectively, in the longitudinal and transverse directions, causing significantly visible superstructure offset.

Figure $4 \mathrm{~b}$ plots the force diagram for the bonded bridge elastomeric bearings, which can help understand the failure pattern of bearings associated with connecting bolt fracture. It can be seen from Fig. $4 \mathrm{~b}$ that for a bridge with a flexural deformationdominated substructure, in addition to the common shear and vertical forces, the bonded elastomeric bearings would be also subjected to the pure bending moment that is induced by the rotation at the substructure top. All these three force components would generate bending moments around the neutral axis on the bearings, as indicated in the Fig. 4b. When the bending moments from different sources are superimposed, the largest moment would occur at the top and bottom sides of the bearings where the connecting set bolts are installed. Hence, the set bolts are very likely to experience large and complicated local stresses that is the direct cause of bolt fracture. In the $2016 \mathrm{Ku}$ mamoto earthquake, such bolt fracture damages were extensively observed in the elastomeric bearings of the Okirihata Oh-hashi Bridge. Goto et al. (2017a, b) noticed such a damage mechanism and studied the possible causes of that. They conducted shake table tests to reproduce and justify the assumed damage mechanism. Although it 
is evident that the aforementioned pure bending force component has an adverse effect on the seismic response of bonded elastomeric bearings in terms of their set bolts, the current Japanese design code unfortunately does not consider this force component in seismic design of bridge elastomeric bearings. Goto et al. (2017a, b) improved the current code design method of bonded elastomeric bearings by incorporating the bearing pure bending behavior under bi-directional earthquake excitations. Using the new design method, the seismic failure risk of bearing set bolts could be significantly reduced.

\section{Effect of bearing bonding or unbonding on bridge seismic performance}

The effect of bearing bonding or unbonding on the seismic performance of bridges can be discussed from two perspectives, which are the seismic demands of superstructure displacement and substructure force. Regarding the superstructure displacement demand, it can be predicted that the fully bonded elastomeric bearings would lead to a smaller superstructure displacement than the fully unbonded ones. This is because that the bonding facilitates the full use of shear stiffness of the elastomeric bearings, which can better restrain the lateral displacement of superstructure. Moreover, when it comes to displacement restrainers like shear keys, the effectiveness of restrainers can be greatly affected by the installation method of elastomeric bearings, where the bearing unbonding will probably reduce the pre-designed function of restrainers, as indicated in the study of Xiang and Li (2018). For the substructure force demand, it should be noted that the force demand is usually in contrary with the displacement demand, which means that a larger force leads to a smaller displacement and vice versa. Hence, it can be implied that the bonded elastomeric bearings would impose larger force demands on substructure than the unbonded bearings at the same level of earthquake hazard.

Figure $5 \mathrm{a}$ and $\mathrm{b}$ show the typical experimental hysteretic curves of bonded and unbonded elastomeric bearings, respectively. It can be seen from Fig. 5a that for typical laminated elastomeric bearings in Japan, the bearings exhibit approximately linear elastic response at the strain amplitude range lower than $200 \%$. Within such a strain range, the shear stress of the bearings can also be easily calculated by using the specified shear modulus of rubber. However, when the shear strain exceeds $200 \%$, the shear stress of the bearings increases dramatically, showing a significant strain hardening effect. For example, the increase in shear stress from $100 \%$ strain to $200 \%$ strain is around 1.0 $\mathrm{MPa}$, while from $200 \%$ to $300 \%$, the shear stress increase is $5.7 \mathrm{MPa}$. This implies that under larger than expected earthquake hazards, the fully bonded elastomeric bearings may transmit extremely large force demands to bridge substructures, causing their premature yielding or failure that may not be able to predict using the normal linear elastic method. In Fig. 5b showing the hysteresis of unbonded elastomeric bearings, it is seen that with the increase of bearing shear strain, the bearing stress first increases and then decreases as a result of a series of processes from shear deformation, curling and squeezing, sliding, and lift-up to rotation-induced instability. The peak stress capacity of an unbonded elastomeric bearing is usually governed by the sliding-rotation mechanism rather than the shear capacity of the bearing body. The shear stress of the unbonded bearing at $100 \%$ strain amplitude is $0.28 \mathrm{MPa}$, compared with the corresponding value of 1.2 MPa for the bonded bearing. 


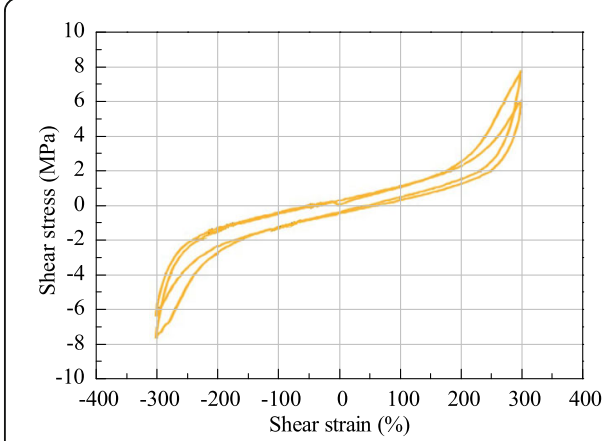

(a) Bonded

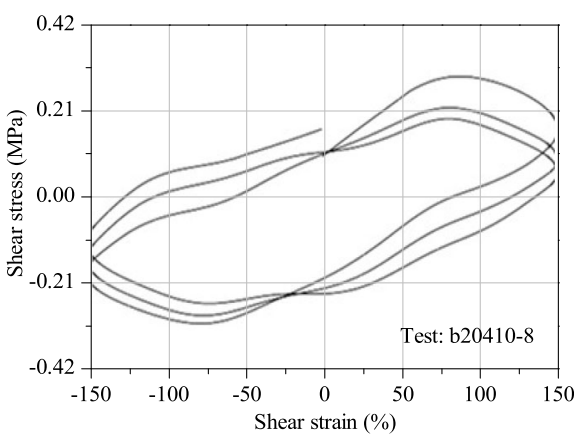

(b) Unbonded

Fig. 5 Experimental cyclic hysteresis of fully bonded (PWRI 2020) and unbonded (Konstantinidis et al. 2008) elastomeric bearings

Considering the effect of fully bonding and fully unbonding on the seismic performance of bridges, it is proposed to design a single-side bonded installation for bridge elastomeric bearings, which is expected to show a better performance. Compared with the fully bonded ones, the single-side bonded bearings show a limited shear stress response that is upper-bounded by the sliding frictional force occurred at the unbonded surface of the bearing. Such a limited shear stress can provide an isolated response for bridge substructure. When compared with the fully bonded bearings, the response of the single-side bonded bearings is more stable without the rolling-over tendencies due to the restraints of curling deformations at the bonded surface. Figure 6 gives the comparison of predicted behaviors for different installation methods of bridge elastomeric bearings. From the lateral force-displacement response shown in Fig. 6a, it is seen that the force-displacement curve of the single-side bonded elastomeric bearings locates between the curves of fully bonded and unbonded bearings, showing an approximately elasto-perfectly-plastic response. The bearing shear force can be well controlled while at the same time, a relatively stable response is also maintained by using the single-side bonded elastomeric bearings. Figure $6 \mathrm{~b}-\mathrm{d}$ shows the rotation induced response of the three different elastomeric bearings. By bonding the top and bottom surfaces, the elastomeric bearings would generate local tensile stress subjected to the bending moment action (Fig. 6b), which may lead to the damages like the delamination between rubber and steel shims, rubber tearing, and fracture of connecting bolts. If the unbonding method is adopted for elastomeric bearings, the local tensile stress can be effectively released by generating the lift-off deformations at the unbonded surfaces (Fig. 6c and d). Regarding the substructure force demand, it is indicated that the superstructure rotation induced bending moment can also be well isolated from being transmitting to
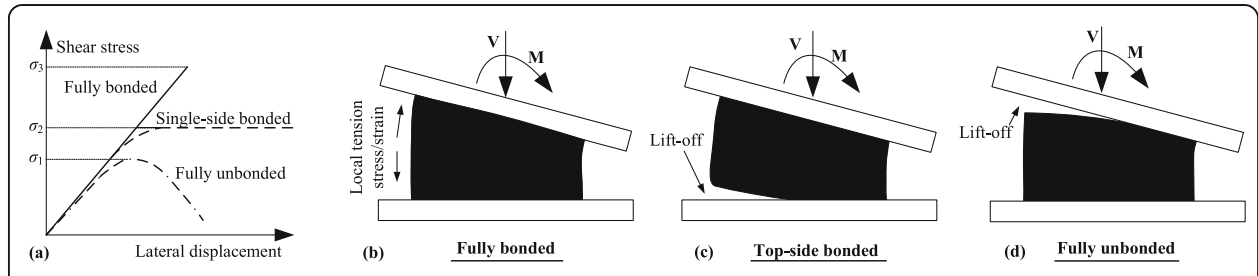

Fig. 6 Comparison of predicted behaviors among different bearing installation methods 
the substructure when unbonded strategies (either single-side bonded or fully unbonded) are used, similar to the case associated with shear force.

The analytical lateral force-displacement formulations for bridge elastomeric bearings with different bonding installations are presented as follows, which have been verified through experimental tests.

Fully bonded: $F_{s}=K_{s} d_{s}, K_{s}=\frac{G_{s} A}{t}$

Fully unbonded: $F_{s}=K_{H} d_{s}, K_{H}=\frac{G_{s} A}{t}(1-\gamma \lambda), \lambda=\frac{t}{2 b}$

Single - side bonded: $F_{s}=K_{e} d_{s}$, when $d_{s}<d_{c} ; F_{s}=P \mu$, when $d_{s} \geq d_{c}$

In these equations, $F_{s}$ and $d_{s}$ are lateral force and displacement, respectively; $K_{s}$ is elastic shear stiffness of fully bonded elastomeric bearings, which is calculated from the conventional shear modulus $\left(G_{s}\right) ; K_{H}$ is varying shear stiffness of fully unbonded bearings, that reduces with the increase of shear strain; $t$ and $2 b$ are rubber height and width of bearings; $K_{e}$ is effective shear stiffness of single-side bonded elastomeric bearings taking the curling deformation into account, which is around $0.6-1.1 K_{s} ; d_{c}$ is critical sliding displacement, and $\mu$ is sliding coefficient of friction at the bearing-support contact surface. Using the Eqs. (1), (2) (Konstantinidis et al. 2008), and (3), the lateral force-displacement relationship of different bearings can be well obtained, as previously shown in Fig. 5a. Such equations can also be used to establish the analytical models for numerical simulation, which is expected to provide a satisfactory estimate of the seismic response of bridges.

\section{Single-side bonding: a seismic fusing design of bridge elastomeric bearings}

Using the stable sliding frictional response of the single side bonded elastomeric bearings, the bearings can be designed as seismic fusing components of bridges, which provides a quasi-isolated seismic response for bridge substructure. The role of the singlesided bonded bearings can be divided into two stages: in the first stage where seismic loads are small, the bearings display linear elastic shear responses to restrain the displacement of superstructure; in the second state when earthquake amplitudes become large, the frictional sliding of the bearings is activated, limiting the force further accumulation and protecting the substructure from severe earthquake damages. To prevent the excessive sliding displacement of bearings, energy dissipation restrainers like metallic yielding dampers should be used parallelly along with the bearings. Some critical design issues of the single-side bridge elastomeric bearings for seismic fusing implementations are discussed in this section.

\subsection{Option of bonding position}

For the single-side bonded elastomeric bearings, the bonding position can be either chosen at the top or the bottom surfaces of the bearings. Considering the seismic fusing role designed for the single-side bonded bearings, it is recommend that the top-side bonding to bridge superstructure is preferred for such a design strategy due to the following reason: since bridge substructure generally has a larger size than superstructure girders, it can be better suited for the bearing frictional sliding response by providing a longer sliding length. Actually, steel girder 
bridges in the United States have already started to use such a top-side bonding method for bridge elastomeric bearings (AASHTO/NSBA 2004), as shown in Fig. 7. Besides, bridges in Illinois also adopt such a top side bonded installation for elastomeric bearings (Filipov et al. 2013a; Filipov et al. 2013b). The elastomeric bearings can be bonded to the steel girders through either welding or bolting methods. The bottom surface of the bearings is seated directly on the wide concrete substructure. Although using the top-side binding method is primarily intended for the convenience of installation in the American code (AASHTO/ NSBA 2004), it provides some potentials for the fusing responses of elastomeric bearings during large earthquakes.

The cyclic behaviors of top-side bonded bridge elastomeric bearings under lateral loads were experimentally investigated by using quasi-static tests (Xiang and Li 2017), as shown in Fig. 8. The experimental test shown in Fig. 8 adopted an elastomer-to-steel contact surface. It can be seen from the figure that under the lateral imposed loads, the curling and squeezing deformations of the top-side bonded elastomeric bearings only appeared at the bottom surface that was also the sliding surface. The experimental lateral force-displacement hysteresis of the bearings was also wide and stable, showing a substantial energy dissipation capacity. A similar test was conducted by Steelman et al. (2013), where an elastomer-to-concrete sliding surface was used, which also displayed a strong energy dissipative hysteretic response.

\subsection{Effective shear stiffness}

Generally, the shear stiffness of a laminated elastomeric bearing can be calculated by using the conventional method as given in Eq. (1), where the shear modulus is obtained through experiments which impose lateral loads on fully bonded rubber specimens. However, for the single-side bonded elastomeric bearings, the shear stiffness of the bearings is usually lower than the normal values due to the participation of curling deformations. The experimental study conducted by Xiang and Li (2017) defined an effective shear stiffness for the single-side bonded elastomeric bearings, which is a secant stiffness reaching from the zero point to the point indicating the occurrence of obvious sliding. The obvious sliding is seen when the shear deformation of elastomeric bearings reaches its peak. Since the shear modulus has a direct correspondence with the shear stiffness, it is

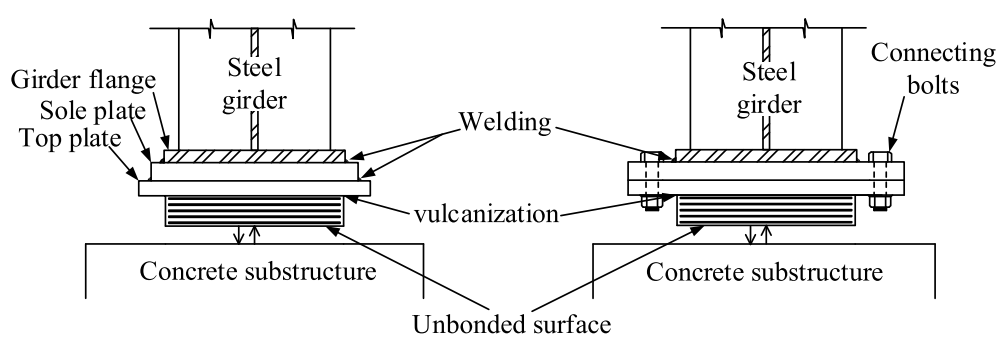

AASHTO/NSBA: Welding

AASHTO/NSBA: Bolting

Fig. 7 Top side bonded bridge elastomeric bearings adopted in the American code (AASHTO/NSBA 2004) 


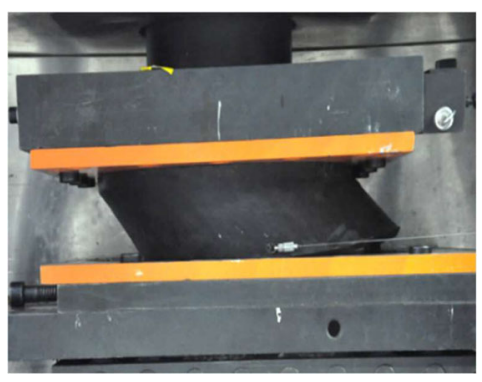

(a) Test setup

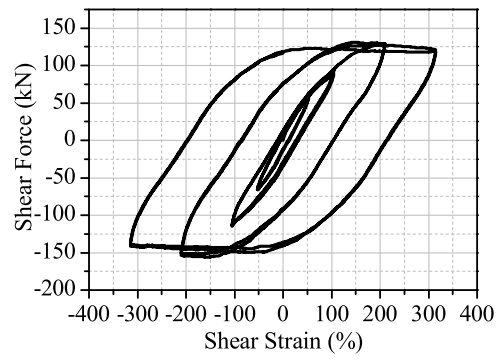

(b) Hysteresis curve

Fig. 8 Quasi-static cyclic tests on seismic behavior of top-side bonded bridge elastomeric bearings

appropriate to evaluate the stiffness of elastomeric bearing by using the shear modulus. Table 1 shows the different methods to determine the shear modulus of elastomeric bearings from the experimental curves in various design codes, where all the codes use the secant line method to determine the elastic shear modulus of elastomeric bearings.

Table 2 lists the calculated shear moduli from different code methods based on the experimental results of Xiang and Li (2017). It can bee seen from Table 2 that the effective shear modulus for the single-side bonded elastomeric bearings, $G_{e}$ was found lower than the values obtained from the methods in ASTM D4014 (2007) and AASH TO M251 (2008), while larger than the values specified in MTC (2019). The effective strains defined by the ratio of imposed lateral displacement to total rubber height, which accounts for the contribution of curling deformation, were in the range from $194 \%$ to $268 \%$. It should be noted that prior to the obvious sliding strain point, the effective strains of the single-side bonded elastomeric bearings are composed of pure shear strain in rubber and curling deformation at the sliding surface.

\subsection{Sliding coefficient of friction}

Since the seismic sliding behavior plays an important role in the performance of singleside bonded elastomeric bearings, it is essential to investigate the sliding coefficient of friction between elastomeric bearings and concrete or steel surfaces. The maximum transmitted force through elastomeric bearings to substructure depends on the selection of the sliding coefficient of friction. Actually, experimental testing is always the most convincing method to reveal the true values of frictional coefficient, which is also the basis of the code specified values for design purposes. The coefficients of friction

Table 1 Different methods determining shear modulus of elastomeric bearing

\begin{tabular}{|c|c|c|c|c|c|}
\hline Method & Denotation & $\begin{array}{l}\text { Shear stress_1 } \\
(\mathrm{kPa})\end{array}$ & $\begin{array}{l}\text { Shear stress_2 } \\
(\mathrm{kPa})\end{array}$ & $\begin{array}{l}\text { Shear strain_1 } \\
\text { (\%) }\end{array}$ & Shear strain_2 (\%) \\
\hline ASTM 4014 & $G_{1}$ & Stress at P1 & Stress at $P 2$ & 0 & 25 \\
\hline $\begin{array}{l}\text { AASHTO } \\
\text { M251 }\end{array}$ & $G_{2}$ & Stress at P1 & Stress at P2 & 0 & 50 \\
\hline MTC (2019) & $G_{3}$ & 300 & 1000 & Strain at $\mathrm{P} 1$ & Strain at P2 \\
\hline $\begin{array}{l}\text { New } \\
\text { method }\end{array}$ & $G_{e}$ & Stress at P1 & Stress at $P 2$ & 0 & $\begin{array}{l}\text { Strain at obvious } \\
\text { sliding }\end{array}$ \\
\hline
\end{tabular}

P1 and P2 denote the two points in the bearing force-deformation curve chosen to determine the secant shear modulus 
Table 2 Calculated shear moduli from different methods (Xiang and Li 2017)

\begin{tabular}{|c|c|c|c|c|c|}
\hline \multirow{2}{*}{$\begin{array}{l}\text { Test series } \\
\text { (Normal } \\
\text { pressure) } \\
\end{array}$} & \multirow{2}{*}{$\begin{array}{l}G_{1} \\
(\mathrm{kPa})\end{array}$} & \multirow{2}{*}{$\begin{array}{l}G_{2} \\
(\mathrm{kPa})\end{array}$} & \multirow{2}{*}{$\begin{array}{l}G_{3} \\
(\mathrm{kPa})\end{array}$} & \multicolumn{2}{|c|}{ New Method } \\
\hline & & & & $G_{\mathrm{e}}(\mathrm{kPa})$ & Strain at obvious sliding (\%) \\
\hline 1-1 (4.0 MPa) & 1255 & 1077 & 760 & 841 & 194 \\
\hline 1-1 (6.0 MPa) & 1278 & 1073 & 759 & 865 & 217 \\
\hline 1-1 (8.0 MPa) & 1286 & 1108 & 747 & 904 & 220 \\
\hline 1-1 (10.0 MPa) & 1357 & 1030 & 759 & 908 & 233 \\
\hline 2-1 (4.0 MPa) & 1318 & 1081 & 771 & 843 & 227 \\
\hline 2-1 (6.0 MPa) & 1286 & 1047 & 760 & 945 & 248 \\
\hline 2-1 (8.0 MPa) & 1259 & 1084 & 773 & 1025 & 258 \\
\hline 2-1 (10.0 MPa) & 1281 & 1099 & 810 & 1096 & 268 \\
\hline
\end{tabular}

$G_{1}$ is shear modulus determined from ASTM D4014 (2007); $G_{2}$ is shear modulus determined from AASHTO M251 (2008); $G_{3}$ is shear modulus determined from MTC (2019); $G_{\mathrm{e}}$ is shear modulus determined from Xiang and Li (2017)

for bridge elastomeric bearings appeared in literature are listed in Table 3. It is indicated in Table 3 that the code specified frictional coefficients are almost constant values, which facilitates the simple engineering design. An exception is the European code which specifies the effect of normal pressure on the values of frictional coefficient. Generally the coefficients of friction between elastomer and steel are smaller than those between elastomer and concrete because of the more roughness of the concrete surface. In the experimental studies, both quasi-static and shake table tests were adopted. Compared with shake table tests, quasi-static tests for coefficient of friction investigation cost lower, allowing for parametric studies by setting a large number of loading cases. The normal pressure and sliding velocity of elastomeric bearings are the two primary factors to be investigated during the quasi-static tests. Generally, the sliding coefficient of friction has an inverse relationship with normal pressure while relates positively to sliding velocity. Xiang and $\mathrm{Li}$ et al. (2017) established a formulation to calculate the frictional coefficient between elastomeric bearings and steel considering the combined effect of normal pressure and sliding velocity, which can be well implemented into FEM analysis program for dynamic numerical simulation. In the shake table tests conducted by Huang (2009) and Xiang et al. (2018), the dynamic coefficient of friction for elastomer-to-steel contact surfaces is around 0.3-0.4, which is very close to the value specified in Caltrans (2009).

\subsection{Balanced seismic design criterion}

When using the single-side bonded bridge elastomeric bearings for seismic fusing design, there exists a critical design criterion required to be well addressed. For one thing, by allowing the seismic sliding behavior of elastomeric bearings, effective measures should be taken to control the sliding displacement of bearings to prevent unseating damages. The allowable sliding displacement should be determined based on the design earthquake amplitude and support length/width. For another, taking displacement restraining measures like restrainers, the transmitted force demands from bridge superstructure to substructure will inevitably increase. It should be ensured that bridge substructure remain in essentially elastic state with neglectable earthquake damage. Hence, it is a critical criterion that the 
Table 3 Coefficients of friction for bridge elastomeric bearings considering sliding

\begin{tabular}{|c|c|c|c|}
\hline Reference & Method & Contact surface & Coefficient of friction, $\mu$ \\
\hline \multirow[t]{2}{*}{ AASHTO (2014) } & Specification & Elastomer-Concrete & 0.20 \\
\hline & & Elastomer-Steel & 0.20 \\
\hline \multirow[t]{2}{*}{ Caltrans (2009) } & Specification & Elastomer-Concrete & 0.40 \\
\hline & & Elastomer-Steel & 0.35 \\
\hline \multirow[t]{2}{*}{ EN 1337-3 (2005) } & Specification & Elastomer-Concrete & $0.1+\frac{0.9}{m}$ \\
\hline & & Other Surfaces & $0.1+\frac{0.3}{m}$ \\
\hline \multirow[t]{2}{*}{ MHURDC (2011) and MTC (2008) } & Specification & Elastomer-Concrete & 0.15 \\
\hline & & Elastomer-Steel & 0.10 \\
\hline \multirow[t]{2}{*}{ MTC (2019) } & Specification & Elastomer-Concrete & 0.30 \\
\hline & & Elastomer-Steel & 0.20 \\
\hline Schrage (1981) & Quasi-static & Elastomer-Concrete & $0.18+\frac{0.37}{m}-\frac{\sum_{u_{\text {slip }}}}{100}$ \\
\hline \multirow[t]{3}{*}{ Liu et al. (2006) } & Quasi-static & Elastomer-Mortar & $\begin{array}{l}6^{-6} v^{4}-0.0002 v^{3}+0.0022 v^{2} \\
+0.0085 v+0.1969\end{array}$ \\
\hline & & Elastomer-Concrete & $0.0044 v^{2}-0.0221 v+0.2408$ \\
\hline & & Elastomer-Steel & $\begin{array}{l}3^{-6} v^{4}-9^{-5} v^{3}-0.0039 v^{2} \\
+0.0341 v+0.2025\end{array}$ \\
\hline \multirow[t]{2}{*}{ Huang (2009) } & Quasi-static & Elastomer-Steel & $0.17-0.38$ \\
\hline & Shake-table & Elastomer-Steel & 0.30 \\
\hline \multirow[t]{2}{*}{ Fang (2012) } & Quasi-static & Elastomer-Steel & $0.10-0.26$ \\
\hline & Shake-table & Elastomer-Steel & 0.27 \\
\hline Steelman et al. (2013) & Quasi-static & Elastomer-Concrete & $0.25-0.50$ \\
\hline Li et al. (2017) & Quasi-static & Elastomer-Steel & $0.15-0.40$ \\
\hline Xiang and Li (2017) & Quasi-static & Elastomer-Steel & $\begin{array}{l}1.09_{m}^{-0.59} \\
\left(1.09_{m}^{-0.59}-1.02_{m}^{-0.72}\right) \mathrm{e}^{-0.39 \mathrm{v}}\end{array}$ \\
\hline Xiang et al. (2018) & Shake-table & Elastomer-Steel & 0.40 \\
\hline Wu et al. (2018) & Quasi-static & Elastomer-Steel & $0.09-0.24$ \\
\hline
\end{tabular}

$\sigma_{\mathrm{m}}$ is normal pressure on elastomeric bearings, $\delta_{\mathrm{u}-\mathrm{slip}}$ is cumulative slip displacement, and $\mathrm{v}$ is sliding velocity

design of the single-side bonded elastomeric bearings should achieve the reasonable balance between superstructure displacement and substructure force demands during earthquakes, and thus an optimal seismic performance on the bridge system level. Such a response balance mainly relies on the seismic design of displacement restrainers, including the selection of proper restrainer types (e.g., stiffness-based, energy dissipation-based, self-centering-based) (Xiang et al. 2019), and the design of restrainer parameters (e.g., stiffness, initial gap, strength, displacement capacity).

Additionally, the cost-effectiveness is also critical to the design of such a new seismic resistant system considering the sliding of bridge elastomeric bearings. Compared with the conventional isolation systems using Lead Rubber Bearings and High Damping Rubber Bearings, it is expected that the seismic performance of the new system should be comparable if properly designed, yet the overall costs including the costs of initial design and construction, repair and replacement, and maintenance during the lifetime span of bridges should be significantly reduced. Probabilistic loss analysis can be used to evaluate the seismic cost-effectiveness of the proposed bridge system. 


\section{Concluding remarks}

This study presents a discussion associated with the effect of bonding or un-bonding on the seismic performance of bridge laminated elastomeric bearings. Typical bearing damages observed in the past major earthquakes are first reviewed and summarized, from which lessons are learned regarding the conventional seismic design strategies of bridge elastomeric bearings. Based on the learned lessons, a new improved design option is proposed by using top-side bonded elastomeric bearings and considering their potential sliding during earthquakes. Critical design issues in terms of the new bridge bearing system are illustrated. The following conclusions are drawn.

(1) For fully bonded elastomeric bearings, although the shear deformation capacity of bearing rubber can be fully made use of to resist seismic loads, the bonding may induce complicated combination of force components acting on bearings or their connecting members, which is always the direct cause of bearing rupture.

Moreover, at large strain amplitudes, the elastomeric bearings show a substantial increase in stress with significant strain hardening effect, which may pose larger than expected force demands on bridge substructure.

(2) The removal of bonding for elastomeric bearings can effectively release the stress complications. However, it may cause unstable bearing responses with curling and squeezing, slippage, and rolling-over behaviors. Such responses are also the primary causes of the span unseating during strong earthquakes.

(3) The single-side bonded elastomeric bearings show an intermediate response between the fully bonded and unbonded ones. The bearings can not only release the complicated stress concentration found in fully bonded bearings, but also maintain a relatively stable bearing response by displaying a simple frictional sliding behavior. The frictional sliding response of single-side bearings during earthquakes can also provide some isolation, protecting bridge substructure from severe damage.

(4) Regarding the design of single-side bonded bridge elastomeric bearings, the topside bonding option with the sliding surface set at bridge substructure is recommended to accommodate an adequate sliding displacement. The initial shear stiffness of elastomeric bearings before sliding should considering the participation of curling deformations, which is usually smaller than the values obtained from conventional methods. The coefficient of friction between elastomeric bearings and concrete/steel should be well determined since it dominates the transmitted inertia force to substructure. The design of bridges equipped with the single-side bonded elastomeric bearings should satisfy the criterion of balanced seismic demands between superstructure displacement and substructure force. Seismic restrainers should be well selected and designed to achieve this design criterion.

Acknowledgements

Not applicable.

Authors' contributions

Goto and Li proposed the research theme. Xiang collected literature materials and wrote the draft of the manuscript. Alam reviewed and give revision comments on the manuscript. All authors read and approved the final manuscript.

Funding

The current research is financially supported by Japan Society for the Promotion of Science (JSPS) KAKENHI (Grant No. 20 K14811). 
Availability of data and materials

The datasets used in this study are available from the corresponding author on reasonable request.

\section{Competing interests}

The authors declare that they have no competing interests.

\section{Author details}

${ }^{1}$ Department of Civil Engineering, Nagoya Institute of Technology, Nagoya 466-8555, Japan. ²School of Engineering, The University of British Columbia, Kelowna V1V 1V7, Canada. ${ }^{3}$ Department of Bridge Engineering, Tongji University, Shanghai 200092, China.

Received: 26 November 2020 Accepted: 28 January 2021

Published online: 08 February 2021

\section{References}

AASHTO (2014) AASHTO LRFD bridge design specifications, 7th edn. American Association of State Highways and Transportation Officials, Washington, DC

AASHTO M251 (2008) Standard specification for plain and laminated elastomeric bridge bearings. AASHTO M251-06, Washington, DC AASHTO/NSBA (2004) Steel bridge bearing design and detailing guidelines. AASHTO/NSBA Steel Bridge Collaboration, Washington, DC

Akiyama M, Takahashi Y, Hata Y, Honda R (2016) Lessons from the 2016 Kumamoto earthquake based on field investigations of damage to bridges. Int J Earthq Impact Eng 1(3):225-252

ASTM D4014 (2007) Standard specification for plain and steel-laminated elastomeric bearings for bridges. D4014-03, West Conshohocken

Caltrans (2009) Seismic design criteria. Version 2.0. Dept. of Transportation, Sacramento

Chang KC, Chang DW, Tsai MH, Sung YC (2000) Seismic performance of highway bridges. Earthq Eng Eng Seismol 2(1):55-77

EN 1337-3 (2005) Structural bearings-part 3: elastomeric bearings. European Committee for Standardization, Brussels

Fang Y (2012) Research on typical damage of simple supported beam bridge during Wenchuan earthquake and transverse retainer device. Doctoral dissertation, Tongji Univ., Shanghai, China

Filipov ET, Fahnestock LA, Steelman JS, Hajjar JF, LaFave JM, Foutch DA (2013a) Evaluation of quasi-isolated seismic bridge behavior using nonlinear bearing models. Eng Struct 49:168-181

Filipov ET, Revell JR, Fahnestock LA, LaFave JM, Hajjar JF, Foutch DA, Steelman JS (2013b) Seismic performance of highway bridges with fusing bearing components for quasi-isolation. Earthq Eng Struct Dyn 42(9):1375-1394

Goto Y, Ebisawa T, Obata M, Li J, Xu Y (2017b) Ultimate behavior of steel and CFT piers in two-span continuous elevatedgirder bridge models tested by shake-table excitations. J Bridg Eng 22(5):04017001

Goto Y, Okumura T, Ebisawa T (2017a) Shear and bending behavior of rubber bearings and their bolted connections in continuous elevated-girder bridges subjected to multi-directional seismic accelerations. Proc Jpn Soc Civil Eng (Struct Earthq Eng) 73(3):532-551 (in Japanese)

Han Q, Du X, Liu J, Li Z, Li L, Zhao J (2009) Seismic damage of highway bridges during the 2008 Wenchuan earthquake. Earthq Eng Eng Vib 8(2):263-273

Huang X (2009) Experimental and theoretical research on unseating prevention device for continuous bridges. Doctoral dissertation, Tongji Univ., Shanghai, China

JRA (2018) Guidelines of road bridge bearings. Japan Road Association, Tokyo (in Japanese)

Kawashima K (2012) Damage of bridges due to the 2011 great East Japan earthquake. J Jpn Assoc Earthq Eng 12(4):4_319_ 4_338

Kawashima K, Unjoh S, Hoshikuma Jl, Kosa K (2011) Damage of bridges due to the 2010 Maule, Chile, earthquake. J Earthq Eng 15(7):1036-1068

Konstantinidis D, Kelly JM, Makris N (2008) Experimental investigation on the seismic response of bridge bearings. Earthquake Engineering Research Center, University of California, Berkeley

Li J, Peng T, Xu Y (2008) Damage investigation of girder bridges under the Wenchuan earthquake and corresponding seismic design recommendations. Earthq Eng Eng Vib 7(4):337-344

Li Y, Li Q, Wu Q (2017) Ultimate shear performance and friction sliding response of laminated elastomeric bridge bearings. J Vibroeng 19(8):6301-6312

Liu KY, Chang KC, Wu BX (2006) The role of rubber bearings of the bridges during the 1999 Taiwan Chi-Chi earthquake. In: 8th US National Conference on earthquake engineering, pp 7307-7316

MHURDC (2011) Code for seismic design of urban bridges. CJJ 166-2011, Ministry of Housing and Urban-Rural Development of China, Beijing

MTC (2008) Guidelines for seismic design of highway bridges. JTG/T B02-01-2008, Ministry of Transport of China, Beijing

MTC (2019) Plate type elastomeric pad bearings for highway bridges JT/T 4-2019. Ministry of Transport of China, Beijing

PWRI (2020) Cooperative research report on seismic performance evaluation of elastomeric bearings. Public Works Research Institute, Tsukuba

Schrage I (1981) Anchoring of bearings by friction. In: Joint sealing and bearing systems for concrete structures, world congress on joints and bearings, vol 1. American Concrete Institute, Niagara Falls

Steelman JS, Fahnestock LA, Filipov ET, LaFave JM, Hajjar JF, Foutch DA (2013) Shear and friction response of nonseismic laminated elastomeric bridge bearings subject to seismic demands. J Bridg Eng 18(7):612-623

Wu G, Wang K, Lu G, Zhang P (2018) An experimental investigation of unbonded laminated elastomeric bearings and the seismic evaluations of highway bridges with tested bearing components. Shock Vib 2018, p. 8439321

Xiang N, Alam MS, Li J (2018) Shake table studies of a highway bridge model by allowing the sliding of laminated-rubber bearings with and without restraining devices. Eng Struct 171:583-601

Xiang N, Goto Y, Obata M, Alam MS (2019) Passive seismic unseating prevention strategies implemented in highway bridges: a state-of-the-art review. Eng Struct 194:77-93 
Xiang N, Li J (2016) Seismic performance of highway bridges with different transverse unseating-prevention devices. J Bridg Eng 21(9):04016045

Xiang N, Li J (2017) Experimental and numerical study on seismic sliding mechanism of laminated-rubber bearings. Eng Struct 141:159-174

Xiang N, Li J (2018) Effect of exterior concrete shear keys on the seismic performance of laminated rubber bearing-supported highway bridges in China. Soil Dyn Earthq Eng 112:185-197

\section{Publisher's Note}

Springer Nature remains neutral with regard to jurisdictional claims in published maps and institutional affiliations.

Submit your manuscript to a SpringerOpen ${ }^{\odot}$ journal and benefit from:

- Convenient online submission

- Rigorous peer review

- Open access: articles freely available online

- High visibility within the field

- Retaining the copyright to your article

Submit your next manuscript at $\boldsymbol{\nabla}$ springeropen.com 